\title{
DERIVATIVES OF THE RATIO SPECTRA FOR DETERMINATION OF ACETYLSALICYLIC ACID, ACETAMINOPHEN, AND CAFFEINE IN FIXED-DOSE COMBINATION FORMULATIONS: APPLICATION TO DISSOLUTION STUDIES
}

\author{
JOSE RAUL MEDINA-LÓPEZ*, JOSUE GIOVANI PACHECO PINEDA, PEDRO ALBERTO ROJAS GARFIAS, NICASIO \\ CASTRO CHÁVEZ
}

\author{
Departamento Sistemas Biológicos, Universidad Autónoma Metropolitana-Xochimilco, Mexico City, Mexico
}

Email: rmlopez@correo.xoc.uam.mx

Received: 17 Aug 2020, Revised and Accepted: 17 Sep 2020

\begin{abstract}
Objective: To develop a ratio-derivative spectrophotometric method for the simultaneous quantification of acetilsalycilic acid (ASA), acetaminophen (ACE), and caffeine (CAF) in fixed-dose combination formulations. The proposed method was applied to the reference drug product Excedrin $\AA$ in dissolution studies.

Methods: The method is based on the use of the first-and second-derivatives of the ratio spectra and measurements at zero-crossing wavelengths. The dissolution profiles of ASA, ACE, and CAF were obtained following pharmacopeial conditions, USP Apparatus 2 at 100 rpm and 900 ml of water. Dissolution samples were treated with the proposed UV-derivative method and the results were compared with those obtained with a validated HPLC procedure. The dissolution efficiency was used to compare dissolution profiles (HPLC vs. UV-derivative method).

Results: The method was linear in the range of $5-25 \mu \mathrm{g} / \mathrm{ml}$ of ASA, $2.5-20 \mu \mathrm{g} / \mathrm{ml}$ of ACE, and $1-8 \mu \mathrm{g} / \mathrm{ml}$ of CAF (R² $>0.999, * \mathrm{P}<0.05)$. The precision and accuracy of synthetic mixtures were within acceptable criteria (2.11-3.43\% and 96.78-104.15\%, respectively). Nitrocellulose filters were the best option to filter samples and stability of all drugs was adequate when standard solutions were stored at $4{ }^{\circ} \mathrm{C}$ during 24 h. No significant differences were found between dissolution profiles $(* \mathrm{P}>0.05)$.

Conclusion: The proposed UV-derivative method allows the simultaneous determination of ASA, ACE, and CAF in commercial formulations. The method is simple, accurate, and precise and can be used in dissolution studies. Spectrophotometric methods are of low cost and harmless to the environment and, therefore, a better alternative than chromatographic methods.
\end{abstract}

Keywords: Acetylsalicylic acid, Acetaminophen, Caffeine, Ratio-derivative spectroscopy, Dissolution studies

(C) 2020 The Authors. Published by Innovare Academic Sciences Pvt Ltd. This is an open access article under the CC BY license (http://creativecommons.org/licenses/by/4.0/] DOI: http://dx.doi.org/10.22159/ijap.2020v12i6.39417. Journal homepage: https://innovareacademics.in/journals/index.php/ijap

Acetylsalicylic acid (ASA), acetaminophen (ACE), and caffeine (CAF) are often available in fixed-dose combination formulations. ASA possesses antirheumatic, antipyretic, and analgesic properties and is probably the major consumed drug in the world. ACE, also known as paracetamol, is an antipyretic and analgesic drug, which in contrast with ASA, it has the advantage of not irritating the gastrointestinal mucosa. The effect of both drugs on pain relief can be enhanced by CAF [1].

Taking advantage of the pharmacological properties of ASA and ACE, as well as the synergism caused by CAF, the mixture of these three drugs is used to treat migraine, among other diseases. Migraine is an episodic headache disorder that produces a wide spectrum of pain and associated disability. Migraine attacks include both pain and associated symptoms (nausea, photophobia, and phonophobia) that have a substantial impact on daily functioning. Migraine pain is typically unilateral, pulsating, and often aggravated by routine physical activity [2]. Both environmental and genetic factors play a role in the development of migraine with more than two-thirds cases having familial history and boys are more affected than girls before puberty and women are more affected than men as age increases [3].

By the wide use of this fixed-dose combination formulation generic drug products with ASA, ACE, and CAF are available in the Mexican market. Generic drug products are off-patent formulations that contain the same active pharmaceutical ingredient (API) in the same dose as the reference drug product and they are administered by the same route [4]. The interchangeability of generic drugs is understood to mean the possibility of their mutual replacement or replacement of the original drug in clinical practice [5]. Drug products containing ACE are purchased without a prescription with the potential risk of poisoning due to their inappropriate administration. Besides, the primary degradation product of ACE is $p$-aminophenol that is reported to have teratogenic effects [6].
Bioequivalence studies are the best way to assure that a generic drug product is safe and interchangeable. Before carrying out the in vivo studies, dissolution studies are the basic tool to evaluate the in vitro release performance of drugs, especially in semi-solid or solid oral dosage forms. Both studies are conducted by international regulations based on previously published scientific information [7].

Literature and experimental data indicate that ASA is a highly soluble and highly permeable drug, leading to the assignment of this drug to class I of the Biopharmaceutical Classification System (BCS) [8]. On the other hand, by its high solubility and low permeability ACE is a class III drug [9]. Immediate-release solid oral dosage forms containing ASA or ACE, as the only API, are candidates to waiver in vivo studies $[8,9]$. In biowaiver monographs the risk of assessing bioequivalence for a specific API, based on in vitro rather than in vivo studies, is evaluated under consideration of its biopharmaceutical and clinical properties [8].

The official in vitro dissolution test of fixed-dose combination formulations of ASA, ACE, and CAF is described in the USP [10]. The following conditions must be used: USP Apparatus 2 (paddle) at 100 $\mathrm{rpm}$ and $900 \mathrm{ml}$ of water as a dissolution medium ( $Q$ not less than $75 \%$ of each drug at $60 \mathrm{~min}$ ). Chromatographic determination is the recommended procedure for the quantification of all drugs.

Several authors have summarized different analytical methods for the simultaneous determination of ASA, ACE, and CAF in synthetic mixtures or fixed-dose combination formulations [11, 12]. Chromatographic methods are the most accessible option but they require expensive equipment and generate toxic waste. Electrochemical methods have the advantage of presenting more sensibility, but electrochemical workstations as potentiostat/ galvanostat instruments are not widely available in pharmaceutical laboratories. UV spectroscopic methods are also proposed for 
treatment of drug mixtures $[13,14]$. A couple of articles describe double divisor-ratio spectra derivative methods for the analysis of the ternary mixture of ASA, ACE, and CAF. For the treatment of samples, one of this methods uses solutions of $\mathrm{pH} 11$ [15], a medium that is out of physiological pH range and the other, that was specifically proposed for dissolution studies, has a confusing procedure [16]

In this study, a ratio-derivative spectrophotometric method with measurements at zero-crossing wavelengths is proposed for the simultaneous determination of ASA, ACE, and CAF in fixed-dose combination formulations. The method was developed according a previous UV analysis of a different ternary mixture [17] and the proposed UV-derivative method was applied to the treatment of dissolution samples. Results were compared with those obtained with a chromatographic method.

The ASA, ACE, and CAF standards were purchased from SigmaAldrich Co. (St. Louis MO, USA). The sodium phosphate monobasic and dibasic crystals, as well as methanol HPLC grade and acetic acid, were purchased from J. T. Baker-Mexico (Xalostoc-Mexico). The fixed-dose combination formulation containing ASA, ACE, and CAF $\left(250 \mathrm{mg} / 250 \mathrm{mg} / 65 \mathrm{mg}\right.$, respectively) used was Excedrin ${ }^{\circledR}$ tablets (GlaxoSmithKline Consumer Healthcare Mexico, S. de R. L. de C. V., Mexico). Mexican health authorities have established this commercial brand as the reference drug product to be used in dissolution and bioequivalence studies [18]. Content uniformity and assay tests were performed with the reference drug product according to pharmacopeial conditions [10].

Dissolution profiles of ASA, ACE, and CAF were obtained according to pharmacopeial conditions [10]. The USP Apparatus 2 (paddle) at $100 \mathrm{rpm}$ was used (Sotax AT-7 Smart, Switzerland). Tablets were added on $900 \mathrm{ml}$ of water at $37.0 \pm 0.5{ }^{\circ} \mathrm{C}$ as dissolution medium. Each dissolution profile was determined with 12 replicates. After addition of tablets $5 \mathrm{ml}$ of filtered dissolution samples were withdrawn at $5,10,15,30,45$, and 60 min (for HPLC analysis) and $10,20,30,45$, and $60 \mathrm{~min}$ (for UV-derivative determination). To compare dissolution profiles (HPLC vs. UV-derivative method) the model-independent parameter dissolution efficiency (DE) was calculated and statistically compared using a Student's $t$-test [19]. Significant differences were found if $* \mathrm{P}<0.05$.

For chromatographic analysis, a Knauer HPLC equipment with UV detector and Smartline 3950 autosampler was used. A Knauer Eurospher II $\mathrm{C}_{18}$ column $(5 \mu \mathrm{m}, 150 \times 4.6 \mathrm{~mm})$ was used. As mobile phase a mixture of water: methanol: acetic acid (65:32:3 v/v/v), previously filtered and degased, was used $(1.8 \mathrm{ml} / \mathrm{min})$. Automatic samples of $30 \mu \mathrm{l}$ were inyected into the HPLC and drugs were quantified at $275 \mathrm{~nm}$.

For spectrophotometric analysis, a double beam UV/Vis spectrophotometer (Perkin Elmer Lambda 35, Waltham MA, USA) with 1 -cm quartz cells was used. The operating conditions for UVderivative analysis were first-derivative ( $\left.{ }^{1} \mathrm{D}\right)$ or second-derivative ( $\left.{ }^{2} \mathrm{D}\right)$ mode with scan speed of $240 \mathrm{~nm} / \mathrm{min}$, slit width $2.0 \mathrm{~nm}$, and sampling interval $1.0 \mathrm{~nm}$.

The preparation of standard calibration curves of ASA, ACE and CAF were as follows: $10 \mathrm{mg}$ of each drug were separately added to three $10 \mathrm{ml}$ volumetric flasks. A volumen of $5 \mathrm{ml}$ of methanol was added to ASA and CAF flasks and a volumen of $5 \mathrm{ml}$ of $0.1 \mathrm{M}$ phosphate buffer pH 7.4 was added to ACE flask; then, all flasks were sonicated during $10 \mathrm{~min}$. After this, volumetric flasks were diluted to the mark with $0.1 \mathrm{M}$ phosphate buffer $\mathrm{pH}$ 7.4. From all stock solutions five solutions of each drug, in $0.1 \mathrm{M}$ phosphate buffer $\mathrm{pH} 7.4$, were prepared at determined interval concentrations: 5 to $25 \mu \mathrm{g} / \mathrm{ml}$ of ASA, 2.5 to $20 \mu \mathrm{g} / \mathrm{ml}$ of ACE, and 1 to $8 \mu \mathrm{g} / \mathrm{ml}$ of CAF. Then, the zeroorder spectra of all solutions, from 200 to $350 \mathrm{~nm}$ using 1-cm quartz cells, were recorded and stored. To quantify ASA and CAF, the stored spectra of the standard solutions of ASA and CAF were divided, wavelength by wavelength and by computer aid, by the stored zeroorder spectrum of a solution of $10 \mu \mathrm{g} / \mathrm{ml}$ of ACE. Finally, the ${ }^{1} \mathrm{D}$ of the resulting ratio spectra of ASA and CAF were plotted. The zerocrossing points to quantify ASA and CAF were identified at 244.64 and $254.89 \mathrm{~nm}$, respectively. To quantify ACE, the stored spectra of the standard solutions of ASA and ACE were divided by the stored zero-order spectrum of a solution of $4 \mu \mathrm{g} / \mathrm{ml}$ of CAF. Finally, the ${ }^{2} \mathrm{D}$ of the resulting ratio spectra of ASA and ACE were plotted. The zerocrossing point to quantify ACE was identified at $219.17 \mathrm{~nm}$. At these wavelengths all analytical signals were proportional to the concentrations of the drugs.

To quantify ASA, ACE, and CAF in dissolution samples, the zeroorder spectra of filtered solutions, at adequate concentrations, were recorded and stored. Then, the stored spectra of the samples were divided by the stored zero-order spectra of $10 \mu \mathrm{g} / \mathrm{ml}$ of ACE and 4 $\mu \mathrm{g} / \mathrm{ml}$ of CAF and ASA, ACE, and CAF were quantified according the procedures described above.

To test linearity, three standard calibration curves of each drug were prepared and mean data were plotted. Data were fitted by linear regression analysis and the correlation coefficients and regression analysis of variance were calculated. Precision was demonstrated with the calculation of relative standard deviation (RSD): [(standard deviation/mean) $\times 100$ ] of response factor (proporcionality of response $v s$. drug concentration).

The accuracy and precision were tested with the preparation of three synthetic mixtures in $0.1 \mathrm{M}$ phosphate buffer $\mathrm{pH} 7.4$ from the stock solutions of each drug at following concentrations: 6,18 , and $23 \mu \mathrm{g} / \mathrm{ml}$ of ASA; 3, 12, and $18 \mu \mathrm{g} / \mathrm{ml}$ of ACE; and 2.5, 5, and $7 \mu \mathrm{g} / \mathrm{ml}$ of CAF. Synthetic mixtures were analyzed with the proposed UVderivative method. Added vs. recovered concentrations were plotted and linear regression analysis was calculated. RDS at each level was calculated.

The drug retention by the filter was evaluated considering response of ASA, ACE, and CAF before and after a solution of each drug was filtered. Nitrocellulose and fiberglass filters were tested. Absolute differences (AD): [((initial-final)/initial) $\times 100]$ were calculated with 10 samples. The drug stability was evaluated by stored a solution of each drug at 4 and $25^{\circ} \mathrm{C}$ during 24 and $48 \mathrm{~h}$. The AD was calculated at each temperature and sampling time.

The zero-order spectra of a $0.1 \mathrm{M}$ phosphate buffer $\mathrm{pH} 7.4$ solution of $15 \mu \mathrm{g} / \mathrm{ml}$ of ASA, $10 \mu \mathrm{g} / \mathrm{ml}$ of ACE, $4 \mu \mathrm{g} / \mathrm{ml}$ of CAF, and a synthetic mixture of drugs at same concentrations, are shown in fig. 1A. These concentrations were used as an example of the response of the compounds to the incidence of UV light and represent the central concentration of the standard calibration curves. The zero-order spectrum of the mixture solution demonstrated a marked overlapping so that the direct determination of each drug in this solution was not possible. The zero-crossing point of CAF was found at $244.64 \mathrm{~nm}$. At this point, the ${ }^{1} \mathrm{D}$ of ASA solutions were determined. The zero-crossing point of ASA was found at $254.89 \mathrm{~nm}$. At this point, the ${ }^{1} \mathrm{D}$ of $\mathrm{CAF}$ solutions were determined. Standard calibration curves of ASA and CAF, as well as the synthetic mixture, are shown in fig. 1B. In a ${ }^{2} \mathrm{D}$ plot, the zero-crossing point of ASA was found at $219.17 \mathrm{~nm}$. At this point, the ${ }^{2} \mathrm{D}$ of ACE solutions were determined. Standard calibration curve of ACE and the synthetic mixture are shown in fig. 1C.

Table 1: Linearity of acetylsalicylic acid (ASA), acetaminophen (ACE), and caffeine (CAF)

\begin{tabular}{llll}
\hline Drug & Equation & CI $95 \%$ for intercept & RSD (\%) \\
\hline ASA & $\mathrm{y}=0.0105 \mathrm{x}-0.0016$ & -0.0053 to 0.0021 & 2.80 \\
ACE & $\mathrm{y}=0.2837 \mathrm{x}-0.0021$ & -0.0437 to 0.0396 & 2.54 \\
CAF & $\mathrm{y}=-0.061 \mathrm{x}-0.0049$ & -0.0126 to 0.0027 & 3.16 \\
\hline
\end{tabular}

$\mathrm{n}=3$ 

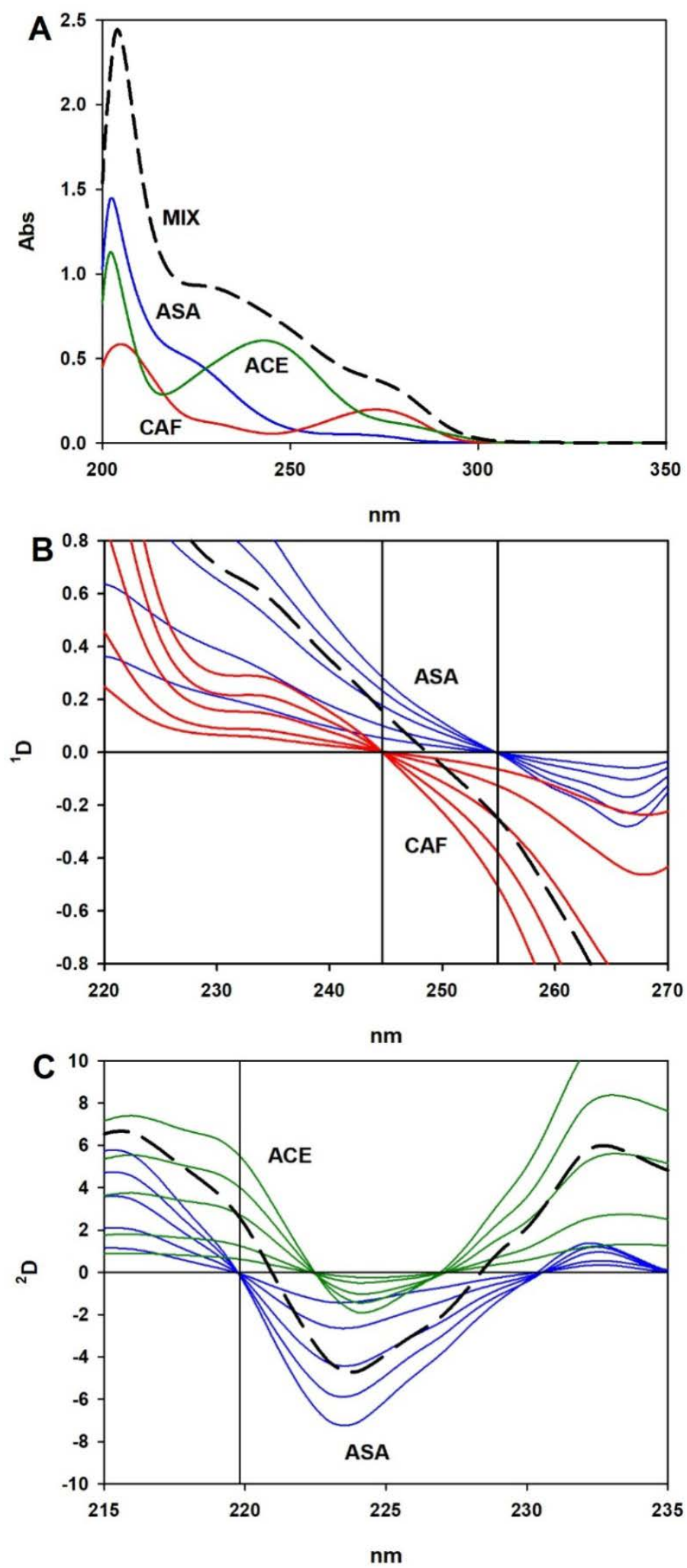

Fig. 1: A) Zero-order spectra of a solution of acetylsalicylic acid (ASA), acetaminophen (ACE), caffeine (CAF), and a synthetic mixture (MIX) with all drugs. B) First derivative ( $\left.{ }^{1} D\right)$ of the ratio spectra of standard curves of ASA, CAF, and MIX. C) Second derivative ( $\left.{ }^{2} D\right)$ of the ratio spectra of standard curves of ASA, ACE, and MIX. Vertical lines show the zero-crossing points used to quantify each drug

To test linearity, three standard calibration curves of each drug were prepared and mean data are shown in table 1 . To test accuracy and precision, added $v s$. recovered concentrations were plotted and linear regressions were calculated. Results are shown in table 2. All linear regressions were significant $\left(\mathrm{R}^{2}>0.999, * \mathrm{P}<0.05\right)$. 
Table 2: Accuracy and precision of acetylsalicylic acid (ASA), acetaminophen (ACE), and caffeine (CAF)

\begin{tabular}{llll}
\hline Drug & Equation & CI $95 \%$ for slope & CI $95 \%$ for intercept \\
\hline ASA & $\mathrm{y}=0.9901 \mathrm{x}-0.2745$ & 0.74 to 1.23 & -4.56 to 4.01 \\
ACE & $\mathrm{y}=1.0279 \mathrm{x}+0.0763$ & 0.95 to 1.10 & -0.85 to 1.04 \\
CAF & $\mathrm{y}=1.0629 \mathrm{x}-0.2065$ & 0.99 to 1.13 & -0.60 to 0.19 \\
\hline
\end{tabular}

$\mathrm{n}=4$

The lowest values of $\mathrm{AD}$ to test the influence of the filter and drug stability are shown in table 3 . The reference drug product met the content uniformity and assay tests described in the USP. Results are also shown in table 3.

Table 3: AD values calculated to test influence of filter and stability with standard solutions and pharmacopeial tests to evaluate quality of reference drug product

\begin{tabular}{|c|c|c|c|c|}
\hline Drug & Influence of filter $(\%)^{a}$ & Stability $(\%)^{b}$ & Content uniformity (min-max\%)c & Assay $(\%)^{d}$ \\
\hline ASA & -0.47 & -16.42 & 94.40 to 112.65 & 95.73 \\
\hline ACE & 0.26 & -16.21 & 92.06 to 99.94 & 99.81 \\
\hline CAF & -0.70 & -50.66 & 96.30 to 112.62 & 98.88 \\
\hline
\end{tabular}

${ }^{a} \mathrm{n}=10$ with nitrocellulose filters, ${ }^{\mathrm{b}} \mathrm{n}=6$ at $4{ }^{\circ} \mathrm{C}$ during $24 \mathrm{~h}, \mathrm{c} n=10, \mathrm{~d} n=3$

Dissolution profiles of ASA, ACE, and CAF are shown in fig. 2. Dissolution performance of each drug, determined with the proposed UV-derivative method, looks like dissolution performance obtained with the HPLC method. As different sampling times were used in each experiment as well as at $5 \mathrm{~min}$ more than $80 \%$ of drug dissolved was found, no $\mathrm{f}_{2}$ similarity factors were calculated. When the model-independent parameter DE was used to compare dissolution profiles (HPLC vs. UVderivative method) no significant differences were found $\left({ }^{*} \mathrm{P}>0.05\right)$. Results are shown in table 4 .
HPLC Method
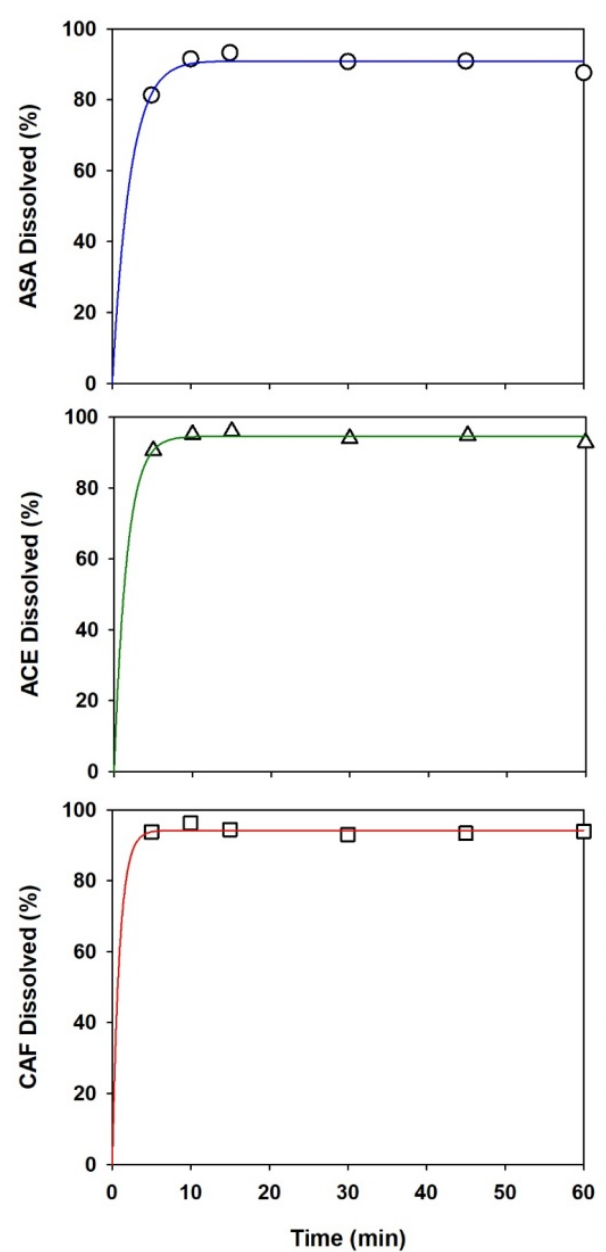

UV-derivative Method
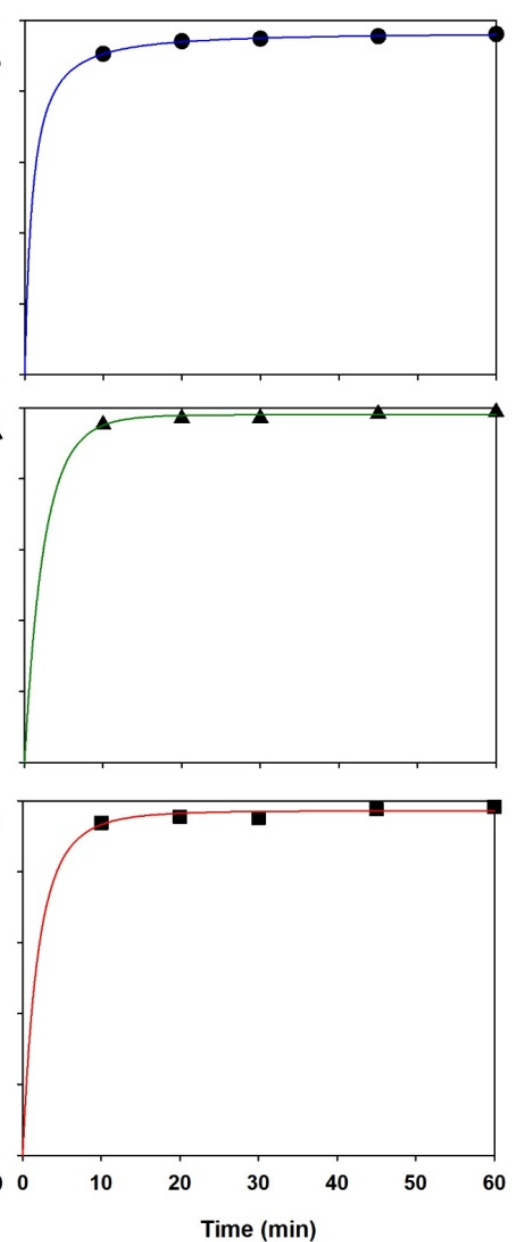

Fig. 2: Dissolution profiles of acetylsalicylic acid (ASA), acetaminophen (ACE), and caffeine (CAF) using the HPLC and UV-derivative methods, mean value, $n=12$ 
Table 4: Dissolution efficiency values calculated with dissolution data of acetylsalicylic acid (ASA), acetaminophen (ACE), and caffeine (CAF)

\begin{tabular}{lll}
\hline Drug & HPLC method & UV-derivative method \\
\hline ASA & $86.31 \pm 0.59$ & $86.37 \pm 0.62$ \\
ACE & $90.26 \pm 0.48$ & $89.19 \pm 0.32$ \\
CAF & $89.95 \pm 0.33$ & $88.04 \pm 1.08$ \\
\hline
\end{tabular}

Mean value \pm standard error medium. $\mathrm{n}=12,{ }^{*} \mathrm{P}>0.05$

The in vitro release performance of ASA, ACE, and CAF was the same when HPLC and UV-derivative methods were used. The proposed spectrophotometric method could be applied with great success for the simultaneous determination of these drugs in fixed-dose combination formulations. Several authors have suggested the use of DE for the comparison of dissolution profiles [19], while this modelindependent parameter is also used to establish level $\mathrm{C}$ in vitro/in vivo correlations [20].

The dissolution behavior of all drugs was fast $(>80 \%$ dissolved at 5 min) so this process could not be the limited-step for the absorption of ASA, ACE, and CAF in the body. By these results the reference drug product is a good parameter to compare generic formulations. There are some considerations for requesting a biowaiver for a fixed-dose combination containing a mixture of class I and III drugs. BCS-based biowaivers are aplicable for immediate-release fixed-dose combination products if they fulfill some excipients considerations e. g. the test product contains the same excipients as the reference drug product. This is due to the concern that excipients can have a greater impact on the absorption of low permeability drugs. The composition of the test product must be qualitatively the same (except for a different color, flavor, or preservative that could not affect the bioavailability) and should be quantitatively very similar to the reference drug product [7].

Several authors have pointed out that owing to the therapeutic use of this drug combination, it is highly needed to develop fast, simple, and reliable methods for simultaneous drug monitoring in pharmaceutical formulations [11]. Ratio-derivative spectroscopy was an analytical approach successfully used to simultaneously identify ASA, ACE, and CAF in the reference drug product. Derivative methods avoid the use of toxic solvents and expensive equipment requering specialized maintenance as a HPLC apparatus. This method is an easy analitical procedure by not needing any additional mathematical calculations or working with dissolution media out of the physiological $\mathrm{pH}$ range. The proposed spectrophotometric method can be used to quantify these drugs in dissolution studies.

\section{FUNDING}

Nil

\section{AUTHORS CONTRIBUTIONS}

All the authors have contributed equally.

\section{CONFLICT OF INTERESTS}

Declared none

\section{REFERENCES}

1. Sena MM, Poppi RJ. N-way PLS applied to the simultaneous spectrophotometric determination of acetylsalicylic acid paracetamol and caffeine. J Pharm Biomed Anal 2004;34:27-34.

2. Silbertein AD, Armellino JJ, Hoffman HD, Battikha JP, Hamelsky SW, Stewart WF, et al. Treatment of menstruation-associated migraine with the nonprescription combination of acetaminophen, aspirin, and caffeine: results from three randomized, placebo-controlled studies. Clin Ther 1999;21:475-91.

3. Bajali O, Amita D, Bairy KL. A complete review of migraine. Asian J Pharm Clin Res 2017;10:57-62.

4. Ruiz ME, Gregorini A, Talevi A, Volonte MG. Dissolution studies of generic medications: new evidence of deviations from the transitivity principle. Dissolut Technol 2012;19:13-24.
5. Shokhin IE, Ramenskaya GV, Vasilenko GF, Malalshenko EA. Assessment of the possibility of using comparative in vitro dissolution kinetics (biowaiver) instead of in vivo bioequivalence evaluation for establishing the interchangeability of generic drugs. Pharm Chem J 2011;45:107-9.

6. Mujahid A, Ali Y, Afzal A, Hussain T, Shah AT, Shehzad K, et al. Rapid assay of the comparative degradation of acetaminophen in binary and ternary combinations. Arab J Chem 2014;7:522-4.

7. Food and Drug Administration. Guidance for Industry: Waiver of in vivo bioavailability and bioequivalence studies for immediaterelease solid oral dosage forms based on a Biopharmaceutics Classification System; 2017. Available from: https://www.fda.gov/media/70963/download. [Last accessed on 16 Aug 2020]

8. Dressman JB, Nair A, Abrahamsson B, Barends DM, Groot DW, Kopp S, et al. Biowaiver monograph for immediate-release solid oral dosage forms: acetylsalicylic acid. J Pharm Sci 2012;101:2653-67.

9. Kalantzi L, Reppas C, Dressman JB, Amidon GL, Junginger HE, Midha KK, et al. Biowaiver monographs for immediate-release solid oral dosage forms: acetaminophen (Paracetamol). J Pharm Sci 2006;95:4-14.

10. United States Pharmacopeia and National Formulary USP42NF37; The United States Pharmacopeial Convention, Inc: Rockville MD; 2019.

11. Yiğit A, Yardim Y, Celebi M, Levent A, Şentürk Z. Graphen/Nafion composite film modified glassy carbon electrode for simultaneous determination of paracetamol, aspirin and caffeine in pharmaceutical formulations. Talanta 2016;158:21-9.

12. Sanghavi BJ, Srivastava AK. Simultaneous voltammetric determination of acetaminophen, aspirin and caffeine using an in situ surfactant-modified multiwalled carbon nanotube paste electrode. Electrochim Acta 2010;55:8638-48.

13. Lotfy HM, Saleh SS. Recent development in ultraviolet spectrophotometry through the last decade (2006-2016): a review. Int J Pharm Pharm Sci 2016;8:40-56.

14. Parmar R, Tandel F, Patel N. Ratio spectra derivative UV spectrophotometric method for simultaneous estimation of ketorolac tromethamine and phenylephrine hydrochloride in an immediate-release tablet. Int J Pharm Pharm Sci 2015;7:13-6.

15. Hajian R, Soltaninezhad A. The spectrophotometric multicomponent analysis of a ternary mixture of paracetamol, aspirin, and caffeine by the double divisor-ratio spectra derivative method. J Spectrosc 2013;405210:7.

16. Markopoulou CK, Malliou ET, Koundourellis JE. Content uniformity and dissolution test of triplicate mixtures by a double divisor-ratio spectra derivative method. Il Farmaco 2005;60:755-62.

17. Berzas Nevado JJ, Guiberteau Cabanillas C, Salinas F. Spectrophotometric resolution of ternary mixtures of salicylaldehyde, 3-hydroxybenzaldehyde and 4hydroxybenzaldehyde by the derivative ratio spectrum-zero crossing method. Talanta 1992;39:547-53.

18. Listado Actualizado de Medicamentos de Referencia 2020/01. Cofepris. Mexico. Available from: https://www.gob.mx/ cms/uploads/attachment/file/534996/listado_de_medicament os_de_Referencia.pdf. [Last accessed on 16 Aug 2020]

19. Anderson NH, Bauer M, Boussac N, Khan Malek R, Munden P, Sardaro M. An evaluation of fit factors and dissolution efficiency for the comparison of in vitro dissolution profiles. J Pharm Biomed Anal 1998;17:811-22.

20. Demirtürk E, Öner L. In vitro-in vivo correlations. FABAD J Pharm Sci 2003;28:215-24. 